\title{
Cutaneous leiomyosarcoma on the face
}

\author{
Nathalia Dias Negrão Murback ${ }^{1}$ \\ Bruna Corrêa de Castro ${ }^{1}$
}

\author{
Luiz C. Takita ${ }^{2}$ \\ Gunter Hans Filho ${ }^{3,4}$
}

DOI: http:/ / dx.doi.org/10.1590/abd1806-4841.20186715

\begin{abstract}
Leiomyosarcoma is a rare skin tumor, most common in white men in the fifth to eighth decades of life. Primary tumors are classified in dermal or subcutaneous, that differ by clinical and prognostic features. They may appear on any site of the body, but are rare on the face. A 54-year-old female was admitted with a 5cm exophytic nodular lesion of 8 months duration on the right cheek, site of previous chronic radiodermatitis. Histopathology revealed spindle-shaped cell neoplasia, positive for smooth muscle actin on immunohistochemistry. Cutaneous leiomyosarcomas on the face are rare and may occur in previously irradiated areas. Immunohistochemistry is mandatory for an accurate diagnosis. Its similarity with other tumors may complicate the diagnosis, with delay expansion of the tumor.
\end{abstract}

Keywords: Face; Leiomyosarcoma; Neoplasms; Radiotherapy; Soft tissue neoplasms; Surgical procedures, elective; Surgical procedures, operative

\section{INTRODUCTION}

Leiomyosarcoma is an uncommon smooth muscle malignant tumor, usually intra-abdominal or retroperitoneal. Cutaneous leiomyosarcomas are extremely rare, and represent $2 \%$ to $3 \%$ of soft tissue sarcomas. ${ }^{1}$ They affect Caucasian individuals in $75 \%$ of cases and are 2 - to 3-times more common in men. They can appear at any age, but are more commonly seen between the fifth and eighth decades of life. ${ }^{1-3}$

Cutaneous leiomyosarcomas can be primary or metastatic. The primary forms are classified into dermal or subcutaneous, which have different management and prognosis. ${ }^{1}$ Such classification depends on the percentage of the surface of the tumor that is present in the dermis: more than $90 \%$ for dermal tumors and less than $90 \%$ for subcutaneous. ${ }^{4}$ Dermal tumors usually arise from the arrector pili muscle, whereas the subcutaneous arise from the smooth muscle from the vessels. ${ }^{1}$

They present as solitary and circumscribed nodules. Dermal tumors usually reach 2 to $3 \mathrm{~cm}$ in diameter, while subcutaneous tumors grow larger than $2 \mathrm{~cm} .{ }^{1,3,4}$ Pain, edema, pruritus and paresthesia could be associated..$^{1,4}$ These tumors occur on any part of the body, but rarely affect the face. .,3 $^{1,3}$
The prognosis of dermal tumors is almost always good, are cured by excision, recur in $30 \%$ to $50 \%$ of cases and rarely metastasize. Subcutaneous tumors, the most common, recur more frequently ( $50 \%$ to $70 \%$ ) and show metastasis in $30 \%$ to $60 \%$ of cases, related to the size and degree of differentiation of the lesion. . $^{1,3,4}$

This report presents a case of subcutaneous cutaneous leiomyosarcoma on an area of previous radiotherapy of the face and is relevant due to its clinical rarity.

\section{CASE REPORT}

A 54-year-old female patient reported the appearance of a progressively enlarging nodule on the right cheek, associated to local pain, over the previous 8 months. She had past history of a nodular basal cell carcinoma 12 years previously on the same site, that was treated with excision and radiotherapy, progressing with chronic radiodermatitis. The dermatological examination revealed a 5-cm exophytic nodule on the right cheek, associated to edema of that half of the face (Figure 1). There was no past history of acquired or innate immunosuppression.

\section{Received on 29.11.2016.}

Approved by the Advisory Board and accepted for publication on 13.04.2017.

Study conducted at the Department of Dermatology Dr. Gunter Hans, Hospital Universitário Maria Aparecida Pedrossian, Universidade Federal de Mato Grosso do Sul (Humap-UFMS) - Campo Grande (MS), Brazil.

Financial support: None.

Conflict of interest: None.

\section{Dermatology Outpatient Clinic, Hospital São Julião - Campo Grande (MS), Brazil.}

Discipline of Pathology, Faculdade de Medicina da Universidade Federal de Mato Grosso do Sul (Famed-UFMS) - Campo Grande (MS), Brazil.

Discipline of Dermatology, Faculdade de Medicina da Universidade Federal de Mato Grosso do Sul (Famed-UFMS) - Campo Grande (MS), Brazil.

Medical Residency Program of Dermatology, da Universidade Federal de Mato Grosso do Sul (UFMS) - Campo Grande (MS), Brazil.

MAILING ADDRESS:

Nathalia Dias Negrão Murback

E-mail: nmurback@yahoo.com.br 
The nodule was excised with a shaving, and histopathology showed a monotonous proliferation of a fascicular pattern of spindle-shaped, pleomorphic cells, at times with a whirlwind pattern and interspersed with collagen fibers (Figure 2). Many mitotic figures were found (17 in 10 high power fields) (Figure 3). Immunohistochemistry was positive for smooth muscle actin (SMA) (clone 1A4) and negative for CD34 S100 protein (Figure 4). These findings allowed for the diagnosis of grade 3 leiomyosarcoma according to the Sarcoma Group classification of the Fédération Nationale des Centres de Lutte Contre le Cancer (FNCLCC), France. ${ }^{5}$

The patient was referred to a specialized oncologic service for surgical and radiotherapy treatments. One year later, an ultrasound evidenced foci of metastases to a periglandular lymph node of the right parotid. Pathology was suggestive of spindle-shaped cell sarcoma, which was confirmed by immunohistochemistry panel with positive smooth cell muscle markers (SMA, calponin and muscle actin HHF35) and negative epithelial, fibrohistiocytic, skeletal muscle and melanoma markers.
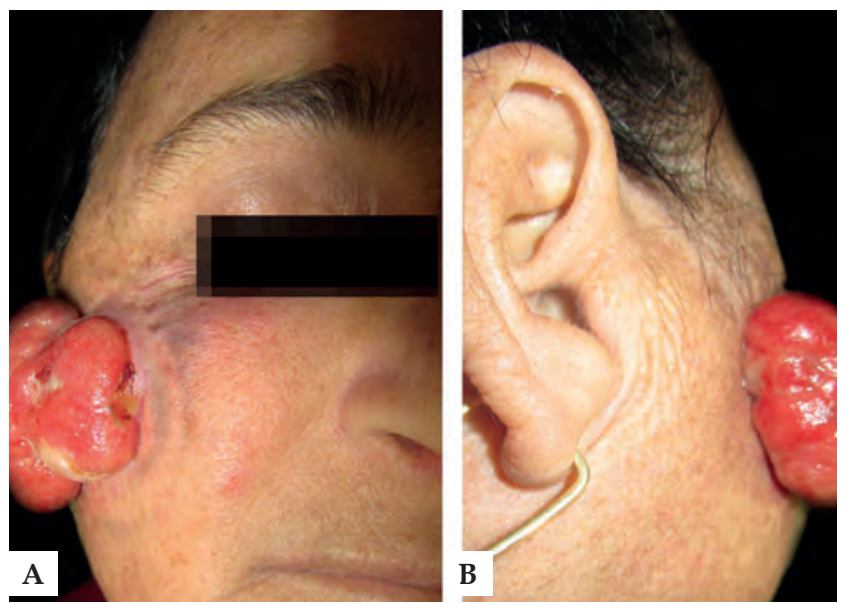

FIGURE 1: Erythematous, vegetating, exophytic, bilobed, friable nodule, with infiltrated borders, $5 \mathrm{~cm}$ in the larger diameter, on the right cheek. A - anterior view; B - posterior view

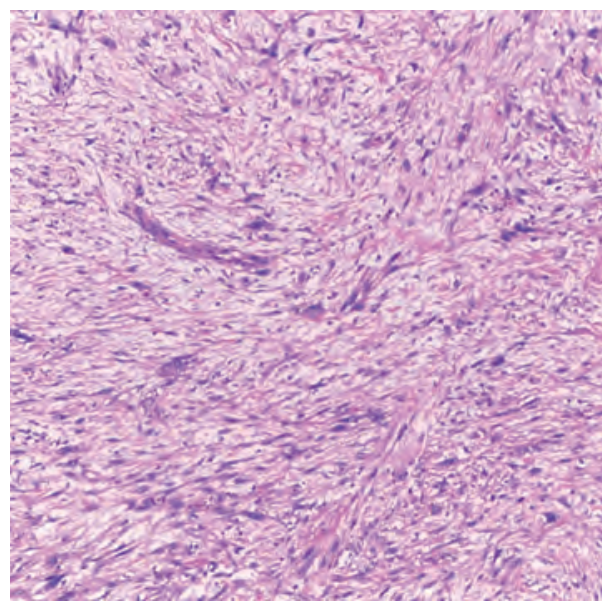

FIGURE 2: Spindle-shaped cells in a fascicular pattern, some with nuclear atypia (Hematoxylin \& eosin, $\mathrm{X} 100)$

\section{DISCUSSION}

Cutaneous leiomyosarcomas occur on any part of the body - $50 \%$ to $75 \%$ on the lower limbs, $20 \%$ to $30 \%$ on the upper limbs, $10 \%$ to $15 \%$ on the trunk - but rarely affect the face $(1 \%$ to $5 \%) .{ }^{1,3}$ In our patient, the malignancy occurred on the face, a rare location.

Trauma, radiation, sun exposure and chemical substances are predisposing factors. ${ }^{6}$ The time from the radiation until the appearance of the leiomyosarcoma can vary from 3 to 24 years; in this case, it occurred after 12 years. $^{2}$

Leiomyosarcoma histopathology shows a spindleshaped cell malignancy, with eosinophilic cytoplasm and nuclei with blunt edges ("cigar-shaped"). Most are well to moderately differentiated. ${ }^{7,8}$ Mitotic figures are easily found, especially in the deeper tumors., ${ }^{3,7}$ There are many differential diagnoses to be considered; immunohistochemistry is essential for an accurate diagnosis (Table 1). ${ }^{4}$

Confirmation of the diagnosis is based in the demonstration of desmin, $\alpha$-SMA (smooth muscle actin $\alpha$ ), muscle actin HHF35

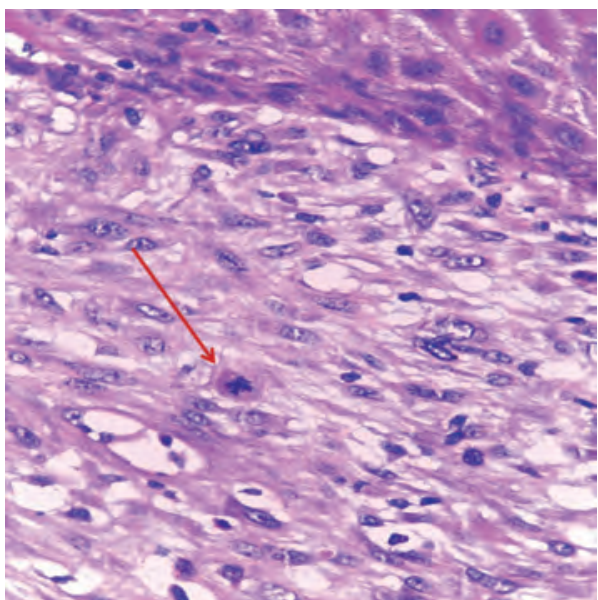

Figure 3: Smooth muscle spindle-shaped cells with mitotic figures (arrow) (Hematoxylin \& eo$\sin , \mathrm{X} 400$

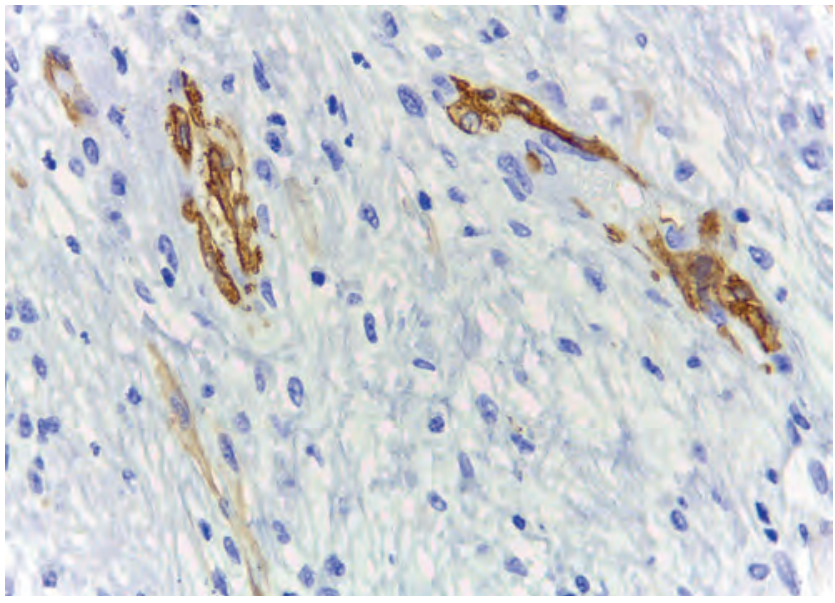

FIGURE 4: Multifocally positive smooth muscle actin (clone 1A4) (immunohistochemistry X400) 


\begin{tabular}{|c|c|c|c|c|c|c|}
\hline & Case & LMS & Melanoma & AFx & SCC & DFSP \\
\hline SMA & $\mathrm{P}$ & $100 \%$ & $-1+$ & $\mathrm{N}$ & $\mathrm{N}$ & $\mathrm{N}$ \\
\hline Desmin & $\mathrm{N}$ & $60 \%$ & $\mathrm{~N}$ & $\mathrm{~N}$ & $\mathrm{~N}$ & $\mathrm{~N}$ \\
\hline $\begin{array}{l}\text { Pan } \\
\text { cytokeratin }\end{array}$ & $\mathrm{N}$ & $\begin{array}{c}30 \%- \\
40 \%\end{array}$ & $\mathrm{~N}$ & $\mathrm{~N}$ & $\mathrm{P}$ & $\mathrm{N}$ \\
\hline Vimentin & $\mathrm{P}$ & $100 \%$ & $\mathrm{P}$ & $\mathrm{P}$ & $\mathrm{N}$ & $\mathrm{P}$ \\
\hline S100 & $\mathrm{N}$ & $-/+$ & $\mathrm{P}$ & $\mathrm{N}$ & $\mathrm{N}$ & $\mathrm{N}$ \\
\hline CD34 & $\mathrm{N}$ & $30 \%$ & $\mathrm{~N}$ & $-/+$ & $\mathrm{N}$ & $\mathrm{P}$ \\
\hline
\end{tabular}

SMA: smooth muscle actin ; LMS: leiomyosarcoma; AFx: atypical fibroxantoma; SCC: squamous cell carcinoma ; DFSP: dermatofibrosarcoma protuberans; P: positive in most tumor cells ; - /+: rarely positive; N: negative. Adapted source: André et al., 2011. ${ }^{5}$

and h-caldesmom. Some studies show that actin and h-caldesmom can be more sensitive than desmin in detecting smooth muscle malignancies. ${ }^{8}$ Leiomyosarcomas express vimentin and SMA in 100\% of cases and desmin in $60 \%$ to $80 \%$ of them. ${ }^{6,8}$ Positivity to at least one of these markers is necessary for the diagnosis. ${ }^{8,9}$ Calponin is a protein related to the smooth muscle that strongly binds to actin.
It is expressed in vascular and parenchyma smooth muscle and is also present in myofibroblasts and myoepithelial cells. ${ }^{8}$ A partial immunophenotypic similarity of leiomyosarcomas with other soft tissue tumors is not uncommon. 8,9

Excision with wide safety margins $(3 \mathrm{~cm}$ to $5 \mathrm{~cm})$, down to the fascia, is recommended for both types. Less than $1 \mathrm{~cm}$ margins are linked to a higher rate of recurrence and metastasis. ${ }^{2,3}$ Regarding survival, no benefit was demonstrated with the use of adjuvant chemotherapy or radiotherapy; nonetheless, radiotherapy is a common choice for high grade tumors. ${ }^{2}$ Mohs micrographic surgery has been showing lower rates of recurrence. ${ }^{1,3}$

Extension to the subcutis, high mitotic index and diameter larger than $1 \mathrm{~cm}$ are morphological features associated to higher recurrence. Advanced age predicts a poorer prognosis, due to the higher incidence of high grade tumors. All patients should be followed up for a minimum of 5 to 10 years. ${ }^{2,3}$

Cutaneous leiomyosarcomas usually metastasize to other cutaneous sites, mainly the scalp; visceral metastases are more common in the lungs, and regional lymph nodes can be affected in up to $25 \%$ of the cases. ${ }^{3,7}$

Cutaneous leiomyosarcomas on the face are rare, and their similarity to other tumors can delay the diagnosis, with subsequent enlargement of the tumor and invasion of adjacent structures. ${ }^{10}$

\section{REFERENCES}

1. Fleury Jr LFF, Sanches Jr JA. Primary cutaneous sarcomas. An Bras Dermatol. 2006;81:207-21

2. Karakatsanis A, Nikolidakis A, Tsavdaris G, Hotzoglou N, Krokos N, Kamas A. Cutaneous Leiomyosarcoma of the scalp. Hellenic J Surgery. 2012;84:324-326.

3. Winchester DS, Hocker TL, Brewer JD, Baum CL, Hochwalt PC, Arpey CJ, et al. Leiomyosarcoma of the skin: clinical, histopathologic, and prognostic factors that influence outcomes. J Am Acad Dermatol. 2014;71:919-25.

4. André MC, Reis MD, Almeida LMS, Antunes JV, Filipe PL. Cutaneous leiomyosarcoma on the trunk. An Bras Dermatol. 2011;86:999-1002.

5. Macarenco RSS, Landman G, Halpern I, Marques MEA. Sarcomas superficiais. In: Bacchi CE, Melo CRA, Franco MF, Artigiane Neto R, editores. Manual de padronização de laudos hiostopatológicos: Sociedade Brasileira de Patologia. 4. ed. São Paulo: Minha Editora; 2014. p. 37-49.
6. Lee KC, Kim MS, Choi H, Na CH, Shin BS. Rapid Growing Superficial Cutaneous Leiomyosarcoma of the Face. Ann Dermatol. 2013;25:237-41.

7. Goldblum JR, Folpe AL, Weiss SW. Soft Tissue Tumors. 6th. ed. Philadelphia: Elsevier; 2014.

8. Doyle LA, Hornick J. Immunohistology of Neoplasms of Soft Tissue and Bone. In: Dabbs, DJ. Diagnostic Immunohistochemistry: theranostic and genomic application. 4th. ed. Philadelphia: Elsevier; 2014. 1v. p. 73-129.

9. Requena L, Kutzner H. Cutaneous Soft Tissue Tumors. Philadelphia: Wolters Kluwer; 2015. p. 278-284.

10. Song H, Yeo I, Lee IJ, Park DH. Huge and Rapdly Growing Superficial Cutaneous Leiomyosarcoma on the Face: Rare Location and Unusual Presentation. $J$ Craniofac Surg. 2013;24:e358-60.

How to cite this article: Murback NDN, Takita LC, Castro BC, Hans-Filho G. Cutaneous leiomyosarcoma on the face. An Bras Dermatol. 2018;93(2):262-4. 